\title{
The relationship between perceived sense of control and visceral adipose tissue - the North Texas Healthy Heart Study
}

\author{
Roberto Cardarelli ${ }^{1,2^{*}}$, Sandy-Asari Hogan ${ }^{1}$, Kimberly G Fulda ${ }^{2,3}$ and Joan Carroll ${ }^{4}$
}

\begin{abstract}
Background: The purpose of this study was to assess the relationship between one's sense of control and visceral adipose tissue.

Methods: This cross-sectional study recruited 571 subjects (45 years and older) who were asymptomatic of CHD from Fort Worth, Texas from 2006 to 2008. Subjects completed a questionnaire, body measurements, a multi-slice computed tomography scan to assess for visceral adipose tissue (VAT) centered at the L4L5 spinal interspace, and serum chemistries. The natural log of L4L5 VAT (InVAT) was used in all analyses to achieve normality of the data with final analyses including 506 participants. Linear regression was used to estimate unadjusted and adjusted beta-coefficients and standard errors for the association between sense of control and InVAT.
\end{abstract}

Results: A total of 506 participants were used in the data after adjusting for normality of the data. An increase in sense of control was associated with a decrease in InVAT in the unadjusted $(p<0.001)$ and adjusted $(p=0.03)$ models. Other factors significantly associated with InVAT in the adjusted model include age, BMI, male gender, non-Hispanic African American, and diet.

Conclusions: Sense of control remained as an independent factor associated with visceral adiposity despite adjusting for traditional cardiovascular risk factors, including BMI. Future studies should focus on establishing a causal relationship between sense of control and visceral adiposity.

Keywords: Sense of control, visceral adipose tissue, cardiovascular, psychosocial

\section{Background}

The burden of excessive weight and its association with adverse health outcomes has been extensively examined by researchers over the years. There has been an increasing amount of interest on the accumulation of visceral adipose tissue (VAT), which is a form of body fat that surrounds various organs of the body. This interest has arisen since VAT is more metabolically active compared to other types of adipose tissue and is known to impact many metabolic abnormalities that have been associated with excessive weight gain [1-10]. Moreover, VAT has been associated with hypertension,

\footnotetext{
* Correspondence: Roberto.Cardarelli@unthsc.edu

'Department of Behavioral and Community Health, School of Public Health University of North Texas Health Science Center at Fort Worth, 3500 Camp Bowie Blvd, Fort Worth, TX 76107, USA

Full list of author information is available at the end of the article
}

insulin resistance, and dyslipidemia [11]. Major factors affecting VAT include sex-hormone imbalance, aging, excessive intake of sucrose, weight gain, genetic makeup, and lifestyle factors including the lack of physical activity, alcohol consumption and cigarette smoking [11]. However, little research has been conducted on the independent influence of psychosocial factors, such as sense of control, on VAT.

Control constructs, such as self-efficacy [12], perceived control [13], and helplessness [14], are examples that have sought to explain and elucidate how "control" interacts with human behavior. Interventions that seek to improve health outcomes must consider the barriers and facilitators to behavioral change; one of which is one's sense of control. Sense of control is the belief that one masters, controls, and shapes one's own life. It is related to self-efficacy and locus of control and has been
C Biomed Central 
found to have adaptive effects which influences emotional wellbeing, physiological changes of stressors, ability to cope with stress, performance, pain, and ability to making difficult behavior changes $[15,16]$.

According to the Theory of Planned Behavior a person's attitude, social norm, and perceived behavioral control influences his or her intentions for behavioral change [17-19]. This implies that individuals are more likely to engage in behaviors over which they have control. Thus, perceived behavioral control is determined by the perceived presence or absence of resources and opportunities and their ability to induce or hinder performance [19]. More research is needed to study the direct and indirect physiological health consequences of sense of control that are mediated through health behaviors. One such objective measure is VAT.

The purpose of the proposed study is to elucidate the association between one's perceived sense of control and VAT, regardless of chronic disease status, smoking behavior, and socioeconomic status.

\section{Methods}

\section{Study population}

The North Texas Healthy Heart (NTHH) study is a cross-sectional study involving a convenience sample of 571 non-Hispanic whites, non-Hispanic African Americans, and Hispanics/Latinos recruited from 12 participating sites of the North Texas Primary Care Practice-Based Research Network (NorTex) from April 2006 to May 2008 (USA). The 12 family medicine/ internal medicine clinic sites that participated in the NTHH study included 4 academic community-based clinics, 3 community health centers, 4 solo-practitioner private practices, and 1 federally-qualified health center. Potential participants were either actively recruited by research coordinators within clinics, referred to the research office by clinic office staff, providers, or active participants, or potential participants directly contacted research staff through advertisements posted in local community newspapers or flyers. Participants were eligible for the study if they were 45 years of age or older, self-identified as non-Hispanic white, non-Hispanic African American, or Hispanic/Latino, and had no history of self-reported cardiovascular disease (coronary artery disease, peripheral arterial disease, history of myocardial infarction or stroke, or congestive heart failure), renal failure, or liver failure. All participants were screened for eligibility either on-site or via phone from a centralized NorTex research office located within the University of North Texas Health Science Center. Initial contact was made with 1,062 individuals, with 860 meeting eligibility criteria. Of those who were eligible, 670 were consecutively invited to participant based on availability of research slots and 571 agreed to participate and the remaining were wait-listed, representing an $85 \%$ recruitment rate (Figure 1). Participants were reimbursed $\$ 60$ for their time and effort in participating in the study. All study procedures were approved by the University of North Texas Health Science Center and JPS Health Network Institutional Review Boards.

\section{Study procedures}

All consented participants underwent a 1-hour face-toface interview. Women, except for those with a history of hysterectomy, underwent a urine pregnancy test, as pregnancy is a contraindication to computed tomography scanning. There were no positive urine pregnancy tests among the study participants. Participants then completed weight, height, waist/hip circumferences, and blood pressure measures (millimeters of mercury $[\mathrm{mmHg}])$. Height was measured to the nearest 0.25 inch, and weight was measured to the nearest $0.25 \mathrm{lb}$ using a standard balance scale. Height and weight measurements were used to calculate a body-mass index for each subject using the Quetelet's equation $\left(\mathrm{kg} / \mathrm{m}^{2}\right)$ [20] Automated Welch Allyn ${ }^{\odot}$ sphygmomanometers were used to measure heart rate and systolic and diastolic blood pressures in each arm using a size-appropriate cuff. The measures were taken after the participant was seated quietly for 5-minutes with both feet flat on the floor and the back comfortably supported. An average heart rate and systolic and diastolic blood pressure was calculated for each subject based on two separate measures.

\section{Demographic and health behavior measures}

The study utilized standardized questions from the Behavioral Risk Factor Surveillance System to collect a selected number of demographic and health behavior information. Age was registered as a continuous variable (years). Race/ethnicity was self-reported and categorized as non-Hispanic white, non-Hispanic African American, Hispanic, and other. Education was measured by the question, "What is the highest grade or year of school that you completed?" Responses were then categorized as "less than high school", "high school graduate/General Equivalency Diploma (GED)", or "some college or greater". Smoking status was assessed by asking, "Have you smoked at least 100 cigarettes in your lifetime?" Subjects were categorized as smokers if they responded "Yes". Diet was assessed by asking how participants rated their diet with examples (i.e., healthy $=$ high in vegetables, low in fat; unhealthy = high in fat, fast foods) and exercise was assessed with the question. "During the past month, other than your regular job, did you participate in any regular physical activities or exercises?" Responses were categorized as "Yes" or "No". 


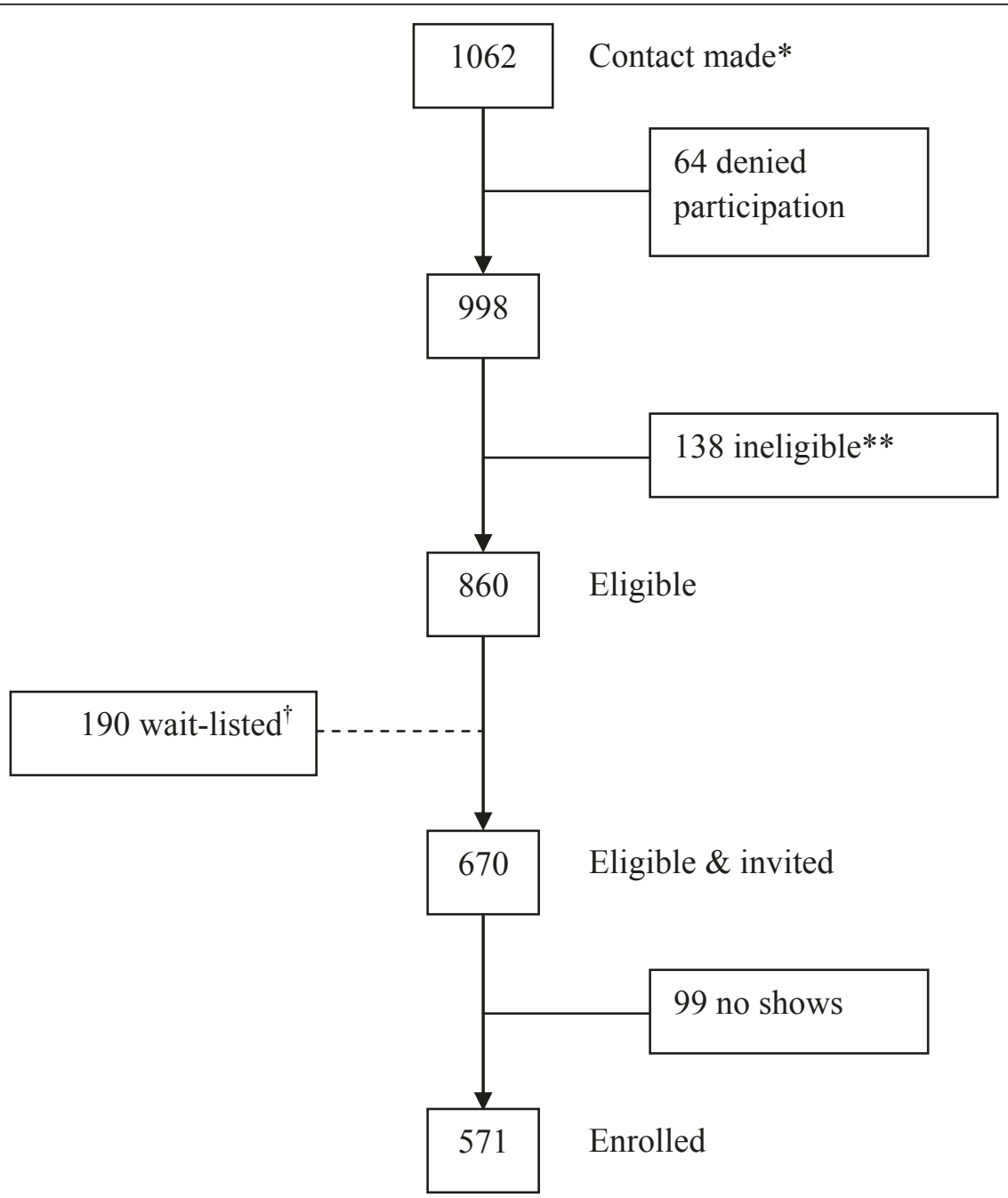

Figure 1 Recruitment flow diagram. * Recruited or participants called the research office. **Based on inclusion/exclusion criteria. tIndividuals were wait-listed if their respective race/ethnicity blocks were full at the time contact was made.

\section{Physiologic and clinical measures}

Visceral adipose tissue (VAT) was measured using a gated 16-slice CT scanner (Toshiba Aquilon 16, Tustin CA). Eight axial CT images of the abdomen were obtained from each subject, with the sixth slice centered on the L4L5 spinal interspace. The cross-sectional areas of VAT were quantified on each slice using softwarederived algorithms (Analyze, version 6.0; Biomedical Imaging Resource, Rochester, MN). The L4L5 VAT measure was used as our dependent variable which is consistent with previous research. Of the 571 participants, VAT measures were obtained on 513 participants and 58 were missing. The absence of VAT measures was due to participant refusal or not showing for their CT scan appointment $(n=36)$ or inability to conduct the CT scan due to physiological limitations, such as tachycardia, morbid obesity and metal prostheses $(n=22)$.
Clinical factors included hypertension, diabetes, and lipid status, and history of a first degree relative with heart disease. Fasting ( 8 hour) blood was collected for serum chemistries and analyzed using a commercial laboratory. History of a first degree relative with heart disease was categorized as yes or no. Hypertension was considered present if the blood pressure was greater than or equal to $140 / 90 \mathrm{~mm} \mathrm{Hg}$ for systolic or diastolic pressure, the subject reported being diagnosed with hypertension, or the subject was taking antihypertensive medications. Diabetes was considered present if the fasting glucose level was greater than or equal to $126 \mathrm{mg} /$ $\mathrm{dL}$, the subject reported being previously diagnosed with diabetes, or the subject was taking any diabetic medication. Hyperlipidemia was considered to be present if the participant had a LDL $\geq 160 \mathrm{mg} / \mathrm{dL}$, the participant reported being previously diagnosed with high 
cholesterol, or the participant was taking a lipid lowering medication.

\section{Sense of control}

The $2 \times 2$ index of sense of control developed by Mirowsky and Ross was used as the primary independent variable for the current analysis (Cronbach $\alpha$ 0.68) [15]. Sense of control is the extent to which an individual perceives having personal power and direction over outcomes in life. Each participant's overall score was calculated as a mean score from eight questions. Responses to each question included a Likert scale ranging from "Strongly agree" (+2 points) to "Strongly disagree" ( -2 points). Higher mean scores indicated a higher sense of control. Sense of control was found to be normally distributed in the study population as depicted in Figure 2.

\section{Statistical analyses}

All statistical analyses were performed using SPSS version 17.0 [21]. Descriptive statistics are provided for all variables. Counts and frequencies are provided for categorical data, and means and standard deviations are provided for continuous variables. Linear regression was performed and unadjusted and adjusted beta-coefficients and standard errors were calculated. Statistical significance was assessed at the alpha $=0.05$ level. Chronic conditions and risk factors, such as hypertension, diabetes, and lipid status, are included in the analyses since their relationship with VAT is a complex and dynamic process. While these chronic conditions may be a consequence of unhealthy lifestyles due to poor sense of control, they may also attenuate the development of VAT through the physiologic distribution of excessive glucose and triggering inflammatory response cascades. Therefore, the authors provide adjusted models including and excluding the chronic conditions to assess changes in the overall impact of sense of control on VAT.

Normality, a required assumption for linear regression analyses, was assessed using stem and leaf plots and skewness and kurtosis statistics for the dependent variable, L4L5 visceral adipose tissue (VAT). After obtaining the natural log of L4L5 VAT (lnVAT), 7 subjects still

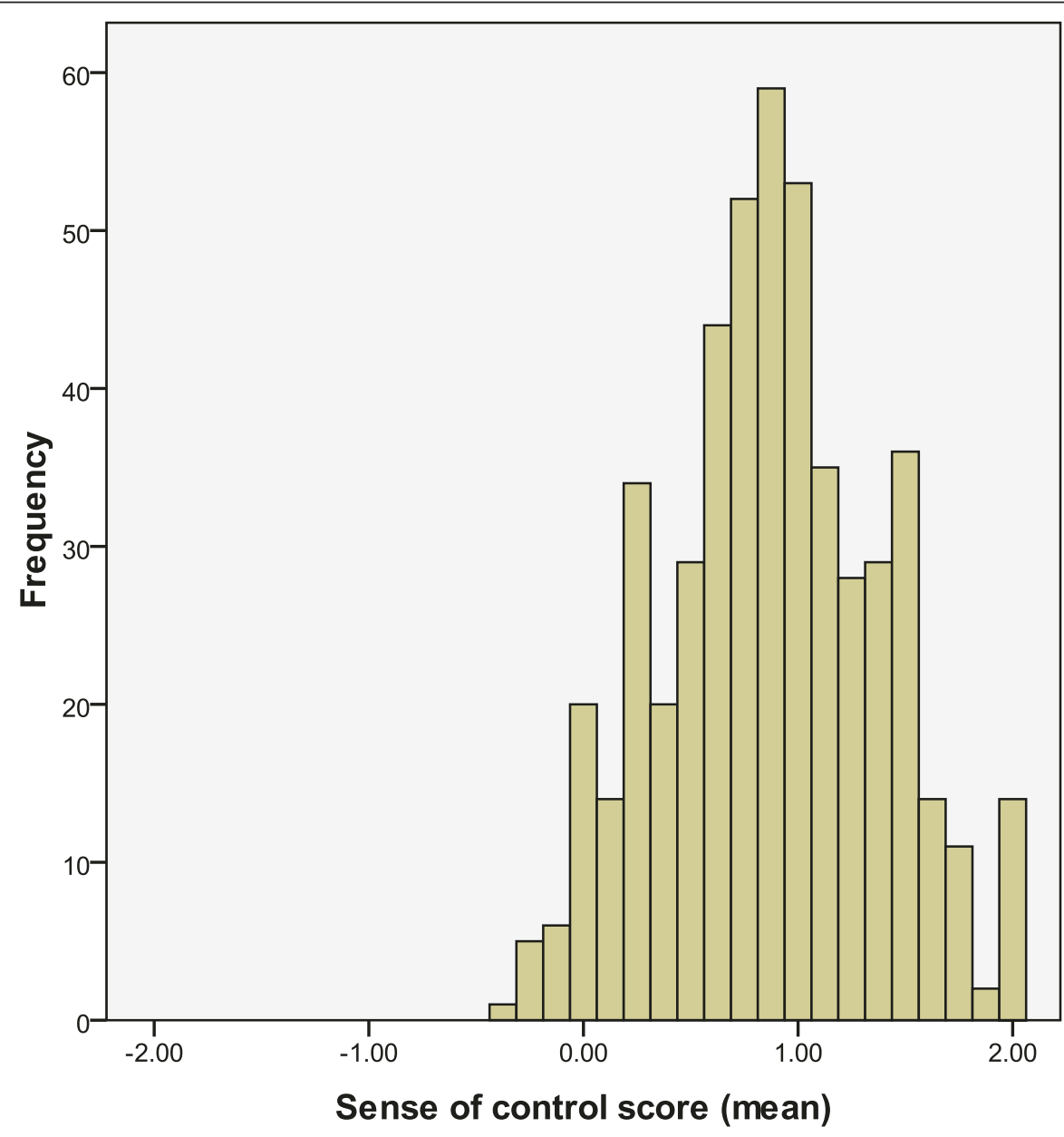

Mean $=0.88$ Std. Dev. $=0.502$ $\mathrm{N}=506$

Figure 2 Sense of control variable distribution histogram. 
needed to be excluded from the analyses as they continued to be significant outliers as determined by stem and leaf plots. The final dependent variable used in all analyses was InVAT. The authors provide a scatter-plot graph (Figure 3) to demonstrate the relationship between VAT and sense of control with the 7 outliers. The adjusted linear regression models also assessed for potential interactions for sense of control"BMI, sense of control"diet, and sense of control"exercise and no interactions were identified. Next, multicollinearity was assessed using Tolerance and Variation Inflation Factor (VIF) with all variables in the final models. No collinear relationships were also identified. The final sample size for all analyses was 506 participants.

\section{Results}

A total of 506 participants were included in the analysis after adjusting for normality. Demographic characteristics are presented in Table 1. For all participants, the median for L4L5 VAT was $351.0 \mathrm{~cm}^{2}(\mathrm{IQR}=170.4)$, and the mean sense of control was $0.8(\mathrm{sd}=0.5)$. On average, subjects were $55.2(\mathrm{sd}=8.1)$ years of age with a BMI of $31.2(\mathrm{sd}=6.6)$. A majority of participants were female $(62.5 \%)$ and had some college or higher (57.5\%). Subjects were non-Hispanic white (27.5\%), non-Hispanic African American (32.8\%), and Hispanic (38.3\%). Of participants, 19.2\% had diabetes, $51.8 \%$ had hypertension, $52.2 \%$ had hyperlipidemia, $49.6 \%$ had a first degree relative with a history of coronary heart disease, and $41.7 \%$ had smoked 100 cigarettes or more in their lifetime. Approximately, $59 \%$ of participants rated their diet healthy, while $70 \%$ reported regular physical activity and/or exercise.

Results of simple and multiple linear regressions are presented in Table 2. Sense of control was significantly associated with lnVAT. Without controlling for other factors, an increase in sense of control was associated with a decrease in lnVAT ( $p<0.001)$. After controlling for potential confounders, with and without chronic conditions, the relationship between sense of control and InVAT remained significant, an increase of sense of control associated with a decrease in $\ln$ VAT $(\mathrm{p}=0.03)$, respectively. Furthermore, all adjusted models did not identify any significant effect modifiers including sense of control"BMI, sense of control"diet, and sense of control"exercise. Risk factors positively associated with lnVAT in crude analysis were increasing age $(\mathrm{p}=0.008)$, increasing BMI $(\mathrm{p}<$ $0.001)$, being male $(\mathrm{p}=0.001)$, having less than a high school degree $(\mathrm{p}<0.001)$, having diabetes $(\mathrm{p}<0.001)$, having hypertension $(\mathrm{p}=0.001)$, healthy diet $(\mathrm{p}<0.001)$ and exercise $(\mathrm{p}=0.03)$. Non-Hispanic African Americans had a lower lnVAT than non-Hispanic whites $(\mathrm{p}<0.001)$ in the crude model. In the both adjusted analyses (i.e., with and without chronic conditions in the models), a significant association remained for age $(\mathrm{p}<0.001)$, BMI ( $\mathrm{p}<$

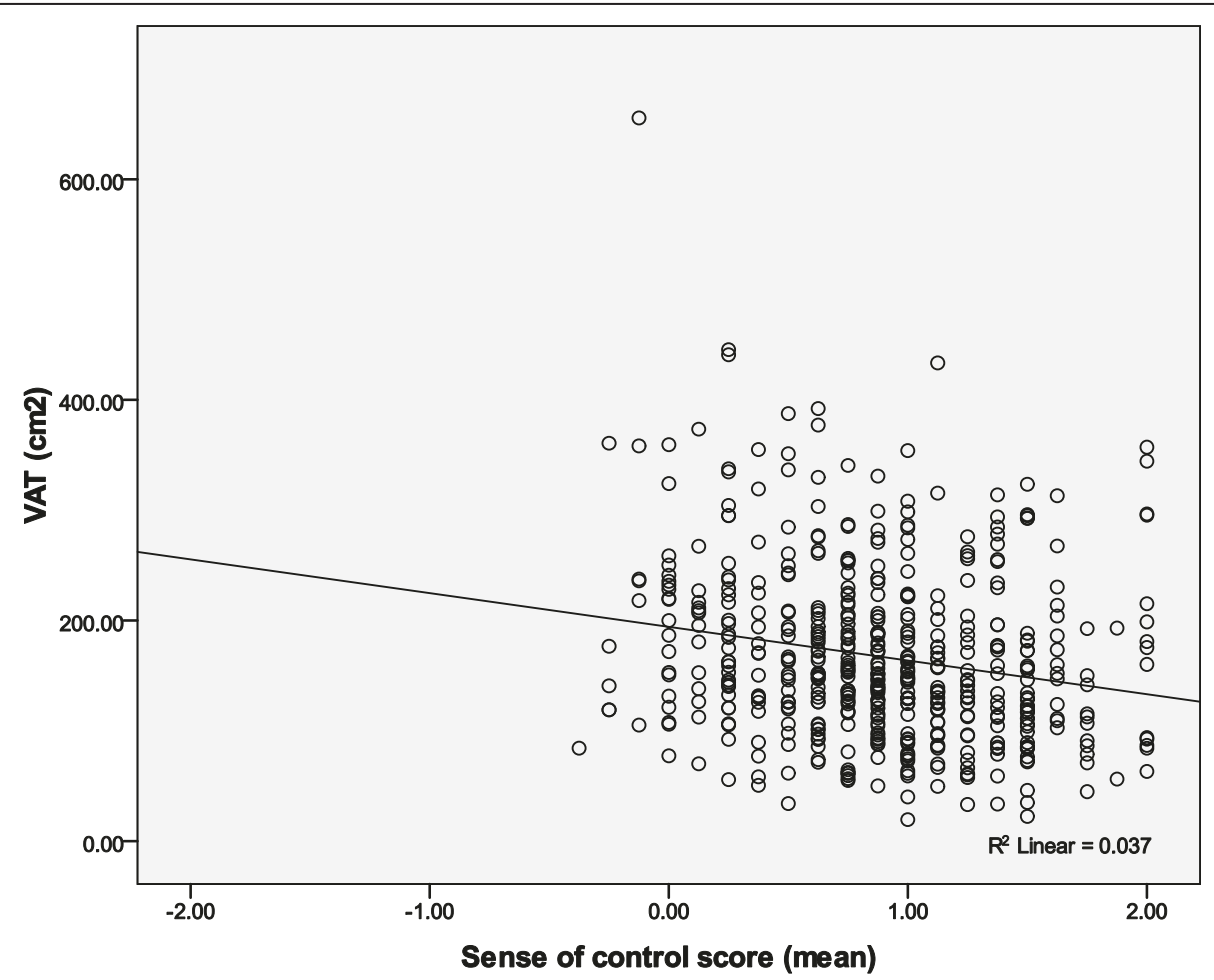

Figure 3 Scatter-plot for VAT and sense of control with outliers 
Table 1 Characteristics of North Texas Healthy Heart study participants - Fort Worth, Texas, USA 2006-8 ( $N=506)$

\begin{tabular}{|c|c|c|}
\hline Variable & $\mathrm{n}^{*}$ & (\%) \\
\hline Age (years), mean (SD) & 55.2 & $(8.1)$ \\
\hline Body mass index $\left(\mathrm{kg} / \mathrm{m}^{2}\right)$, mean (SD) & 31.2 & $(6.6)$ \\
\hline Sense of control score, mean (SD) & 0.8 & $(0.5)$ \\
\hline L4L5 Visceral adipose tissue $\left(V A T, \mathrm{~cm}^{2}\right)$, median (IQR) & 351.0 & $(170.4)$ \\
\hline Natural log VAT, mean (SD) & 5.0 & $(0.5)$ \\
\hline \multicolumn{3}{|l|}{ Gender } \\
\hline Female & 316 & $(62.5)$ \\
\hline Male & 190 & $(37.5)$ \\
\hline \multicolumn{3}{|l|}{ Race/ethnicity } \\
\hline Non-Hispanic white & 139 & $(27.5)$ \\
\hline Non-Hispanic African American & 166 & $(32.8)$ \\
\hline Hispanic & 194 & $(38.3)$ \\
\hline \multicolumn{3}{|l|}{ Education } \\
\hline Less than High school & 113 & $(22.3)$ \\
\hline High school graduate/GED & 102 & $(20.2)$ \\
\hline Some college or higher & 291 & $(57.5)$ \\
\hline \multicolumn{3}{|l|}{ Smoked $\geq 100$ cigarettes in one's life } \\
\hline Yes & 211 & $(41.7)$ \\
\hline No & 288 & $(56.9)$ \\
\hline \multicolumn{3}{|l|}{ Diabetes Mellitus status } \\
\hline Yes & 97 & $(19.2)$ \\
\hline No & 387 & $(76.5)$ \\
\hline \multicolumn{3}{|l|}{ Hypertension status } \\
\hline Yes & 262 & $(51.8)$ \\
\hline No & 124 & $(24.5)$ \\
\hline \multicolumn{3}{|l|}{ Hyperlipidemia status } \\
\hline Yes & 264 & $(52.2)$ \\
\hline No & 227 & $(44.9)$ \\
\hline
\end{tabular}

First degree relative with history of coronary heart disease

\begin{tabular}{lcc} 
Yes & 251 & (49.6) \\
No & 241 & $(47.6)$ \\
\hline Diet rating & & \\
Healthy & 299 & $(59.1)$ \\
Unhealthy & 204 & $(40.3)$ \\
\hline Regularly exercises in the past month & & \\
No & 147 & $(29.1)$ \\
Yes & 356 & $(70.4)$ \\
\hline
\end{tabular}

* May not add up to 506 participants due to missing data. GED, General Equivalency Diploma; IQR, Inter-Quartile Range

$0.001)$, being male $(\mathrm{p}<0.001)$, being non-Hispanic African American $(\mathrm{p}<0.001)$, and $\operatorname{diet}(\mathrm{p}=0.01$ and $\mathrm{p}=0.02$, respectively).

\section{Discussion}

Our results revealed that despite controlling for covariates, including traditional cardiovascular risk factors and
BMI, sense of control was inversely associated with VAT. Our previous research has found that BMI does not necessarily correlate with VAT when stratified by race/ethnicity [22]. This difference is particularly important since VAT is more metabolically active than other forms of adipose tissue and contributes to metabolic abnormalities associated with weight gain [1-10]. Nonetheless, as expected, BMI was positively associated with VAT measures in our study. Subcutaneous adipose tissue (SAT) was not assessed in the present study for its known direct correlation to BMI and waist conference and being less metabolically active, which is outside the scope of the present study. BMI was assessed as a confounder in our study as it may also be a surrogate measure of unhealthy behaviors. Conversely, it may also function as a mediator in the pathway leading from low sense of control to poor lifestyle and elevated VAT. However, analyses did not find BMI to function as a mediating factor. Another consideration to mention is whether chronic conditions, such as hypertension or diabetes, truly functions as confounders in the present study or rather as final outcomes in the pathway. We chose to assess these chronic conditions as confounders due to the complex and dynamic relationship between VAT and chronic conditions. Chronic disease states, such as elevated sugar, can lead to excessive metabolic burden attenuating the development of VAT or triggering metabolic or inflammatory pathways leading to physiologic dysfunction such as elevated blood pressures and downstream adverse health outcomes. Nonetheless, we presented results with and without chronic conditions in the adjusted regression models and determined it did not alter the association between sense of control and VAT. Our results lend to the importance that one's sense of control or mastery has health consequences that are objectively measured. An increase level of understanding of the pathways by which this occurs continue to be an important area of further research, especially studies that identify factors that are amenable to intervention and improved health outcomes.

Our results align well with other published research in that sense of control is associated with health behaviors and conditions that are normally associated with adiposity [23-25]. High sense of control has been found to be protective in the development of diabetes mellitus among adults [23], while lower levels have been associated with a blunted ability to deal with life stressors possibly leading to poor health behavior decisions [26]. In fact, the relationship between sense of control and VAT is most likely a result of having difficulty in changing poor health behaviors or leading one to make unhealthy choices, which in turn harbors the potential to perpetuate the observation of disparate health outcomes. Low sense of control or mastery has previously 
Table 2 Simple and multiple linear regression models predicting natural log of L4L5 visceral adipose tissue (InVAT) Fort Worth, Texas, USA 2006-8 ( $\mathrm{N}=\mathbf{5 0 6}$ )

\begin{tabular}{|c|c|c|c|c|c|c|c|c|c|}
\hline \multirow[b]{2}{*}{ Variable } & \multicolumn{3}{|c|}{$\begin{array}{l}\text { Simple linear } \\
\text { regression }\end{array}$} & \multicolumn{3}{|c|}{$\begin{array}{c}\text { Multiple linear regression } \\
\text { with chronic conditions }\end{array}$} & \multicolumn{3}{|c|}{$\begin{array}{l}\text { Multiple linear regression } \\
\text { without chronic conditions }\end{array}$} \\
\hline & $\beta$ & SE & $p$ & $\beta$ & SE & $p$ & $\beta$ & SE & $\mathrm{p}$ \\
\hline Sense of control & -0.171 & 0.040 & $<.001$ & -0.077 & 0.037 & 0.04 & -0.096 & 0.033 & 0.004 \\
\hline$\overline{\text { Age }}$ & 0.007 & 0.003 & 0.008 & 0.011 & 0.002 & $<.001$ & 0.008 & 0.002 & $<.001$ \\
\hline Body mass index & 0.039 & 0.003 & $<.001$ & 0.042 & 0.003 & $<.001$ & 0.041 & 0.002 & $<.001$ \\
\hline \multicolumn{10}{|l|}{ Gender } \\
\hline Female & $\ldots$ & $\ldots$ & $\ldots$ & $\ldots$ & $\ldots$ & $\ldots$ & $\ldots$ & $\ldots$ & $\ldots$ \\
\hline Male & 0.140 & 0.042 & 0.001 & 0.163 & 0.036 & $<.001$ & 0.188 & 0.032 & $<.001$ \\
\hline \multicolumn{10}{|l|}{ Race/ethnicity } \\
\hline Non-Hispanic white & $\ldots$ & $\ldots$ & $\ldots$ & $\ldots$ & $\ldots$ & $\ldots$ & $\ldots$ & $\ldots$ & $\ldots$ \\
\hline $\begin{array}{l}\text { Non-Hispanic African } \\
\text { American }\end{array}$ & -0.252 & 0.050 & $<.001$ & -0.358 & 0.046 & $<.001$ & -0.319 & 0.040 & $<.001$ \\
\hline Hispanic & 0.050 & 0.049 & 0.31 & -0.025 & 0.049 & 0.61 & 0.008 & 0.043 & 0.86 \\
\hline \multicolumn{10}{|l|}{ Education } \\
\hline Some college or higher & $\ldots$ & $\ldots$ & $\ldots$ & $\ldots$ & $\ldots$ & $\ldots$ & $\ldots$ & $\ldots$ & $\ldots$ \\
\hline Less than High school & 0.211 & 0.050 & $<.001$ & 0.028 & 0.052 & 0.60 & 0.033 & 0.047 & 0.48 \\
\hline $\begin{array}{l}\text { High school } \\
\text { graduate/GED }\end{array}$ & 0.020 & 0.052 & 0.69 & -0.009 & 0.045 & 0.85 & -0.015 & 0.040 & 0.71 \\
\hline
\end{tabular}

Smoked $\geq 100$ cigarettes

in one's life

No

\begin{tabular}{|c|c|c|c|c|c|c|c|c|c|}
\hline Yes & 0.035 & 0.041 & 0.39 & 0.018 & 0.035 & 0.61 & 0.019 & 0.031 & 0.54 \\
\hline \multicolumn{10}{|c|}{ Diabetes Mellitus status } \\
\hline No & $\ldots$ & $\ldots$ & $\ldots$ & $\ldots$ & $\ldots$ & $\ldots$ & & & \\
\hline Yes & 0.244 & 0.050 & $<.001$ & 0.051 & 0.043 & 0.23 & & & \\
\hline \multicolumn{10}{|c|}{ Hypertension status } \\
\hline No & $\ldots$ & $\ldots$ & $\ldots$ & $\ldots$ & $\ldots$ & $\ldots$ & & & \\
\hline Yes & 0.161 & 0.049 & 0.001 & 0.038 & 0.039 & 0.33 & & & \\
\hline \multicolumn{10}{|c|}{ Hyperlipidemia status } \\
\hline No & $\ldots$ & $\ldots$ & $\ldots$ & $\ldots$ & $\ldots$ & $\ldots$ & & & \\
\hline Yes & 0.075 & 0.041 & 0.07 & -0.016 & 0.036 & 0.65 & & & \\
\hline \multicolumn{10}{|c|}{ First degree relative with history of coronary heart disease } \\
\hline No & $\ldots$ & $\ldots$ & $\ldots$ & $\ldots$ & $\ldots$ & $\ldots$ & $\ldots$ & $\ldots$ & $\ldots$ \\
\hline Yes & 0.046 & 0.041 & 0.27 & -0.065 & 0.035 & 0.06 & -0.047 & 0.031 & 0.13 \\
\hline \multicolumn{10}{|l|}{ Diet rating } \\
\hline Healthy & $\ldots$ & $\ldots$ & $\ldots$ & $\ldots$ & $\ldots$ & $\ldots$ & $\ldots$ & $\ldots$ & $\ldots$ \\
\hline Unhealthy & 0.226 & 0.040 & $<.001$ & 0.093 & 0.037 & 0.01 & 0.073 & 0.032 & 0.02 \\
\hline \multicolumn{10}{|c|}{ Regularly exercises in the past month } \\
\hline No & $\ldots$ & $\ldots$ & $\ldots$ & $\ldots$ & $\ldots$ & $\ldots$ & $\ldots$ & $\ldots$ & $\ldots$ \\
\hline Yes & -0.099 & 0.045 & 0.03 & -0.030 & 0.038 & 0.44 & -0.028 & 0.034 & 0.41 \\
\hline
\end{tabular}

$\beta$, Beta coefficient; SE, Standard error; $\mathrm{p}, \mathrm{p}$-value; ...Reference group; GED, General Equivalency Diploma

been shown to be associated with unhealthy food choices [27], low levels of physical performance [28], and smoking [29]. The multi-factorial attributes of economics, environmental factors, internalizing factors, and social pressures all perpetuate unhealthy behaviors and poorer health. The key to sustainable improved health is not only interventions that impact at the individual level, but also numerous changes associated with the social determinants of health, for example safer communities, policy changes, and financial stability.

There are several limitations to the study that must be considered. While sense of control is related to locus of control, self mastery, and self efficacy, it must be realized that these are related but distinct constructs. Also, the sense of control measure used in this study assessed general control of life choices and 
was not specific to health. Since the study was conducted in North Texas, USA, generalizability to other locations remains undetermined. In addition, the crude measures for diet and physical activity may not capture the full assessment of each variable. However, the significant findings demonstrated in the simple regression models provide expected associations between these variable and VAT, hence, reassuring the final conclusions of our study. Finally, the crosssectional nature of the data precludes any causal assumptions.

\section{Conclusions}

Sense of control has been known to be adaptive allowing for focused interventions to function as plausible solutions to change risky and unhealthy behaviors that lead to disease and death. However, the next stages of research need to focus on establishing causality between sense of control and health outcomes. Once causality is established, further interventional research can be performed to assess whether impacting a person's sense of control can lead to improved health behaviors and related outcomes.

\section{Abbreviations \\ VAT: visceral adipose tissue; NTHH: North Texas Healthy Heart; NorTex: North Texas Primary Care Practice-Based Research Network; mmHg: millimeters of mercury; $\mathrm{kg} / \mathrm{m}^{2}$ : kilograms per meter squared; lb: pounds; CT: computed tomography; GED: General Educational Development; InVAT: natural log visceral adipose tissue; VIF: Variation inflation factor; $\mathrm{cm}^{2}$ : centimeter squared; BMI: body mass index' SE: standard error; SD: standard deviation; $\beta$ : beta; $p$ : p-value.}

\section{Acknowledgements}

The authors are grateful for the assistance of Ana L. Chiapa, Mayra Rodriguez, Lorna Brooks and the Primary Care Research Center staff of the University of North Texas Health Science Center. We also want to thank the clinicians of the North Texas Primary Care Research Network who helped recruit study participants. The project described was supported by Grant Number P20MD001633 from the National Institute On Minority Health And Health Disparities and the NIH Loan Repayment Program. The content is solely the responsibility of the authors and does not necessarily represent the official views of the National Institute On Minority Health and Health Disparities or the National Institutes of Health

\section{Author details}

${ }^{1}$ Department of Behavioral and Community Health, School of Public Health University of North Texas Health Science Center at Fort Worth, 3500 Camp Bowie Blvd, Fort Worth, TX 76107, USA. ²Primary Care Research Center/Texas Prevention Institute, University of North Texas Health Science Center at Fort Worth, 3500 Camp Bowie Blvd, Fort Worth, TX 76107, USA. ${ }^{3}$ Department of Family Medicine, Texas College of Osteopathic Medicine, University of North Texas Health Science Center at Fort Worth, 3500 Camp Bowie Blvd, Fort Worth, TX 76107, USA. ${ }^{4}$ Department of Integrative Physiology, Graduate School of Biomedical Sciences, University of North Texas Health Science Center at Fort Worth, 3500 Camp Bowie Blvd, Fort Worth, TX 76107, USA.

\section{Authors' contributions}

RC conceived of the study, design and analyzed the data, and was the primary writer of the manuscript. KGF and SAH assisted in methodology of the study, assisted in data analyses, edited the manuscript. JC oversaw all labs analyses and methodology and edited the manuscript. All authors read and approved the final manuscript.

\section{Competing interests}

The authors declare that they have no competing interests.

Received: 26 April 2011 Accepted: 13 September 2011

Published: 13 September 2011

\section{References}

1. Jensen MD: Adipose tissue and fatty acid metabolism in humans. $J R$ SOC Med 2002, 95(Suppl 42):3-7.

2. You T, Ryan AS, Nicklas BJ: The metabolic syndrome in obese postmenopausal women: relationship to body composition, visceral fat, and inflammation. J Clin Endocrinol Metab 2004, 89(11):5517-22.

3. Ding J, Visser $M$, Kritchevsky SB, et al: The association of regional fat depots with hypertension in older persons of white and African American ethnicity. Am J Hypertens 2004, 17(10):971-6.

4. Colberg SR, Simoneau JA, Thaete FL, Kelley DE: Skeletal muscle utilization of free fatty acids in women with visceral obesity. J Clin Invest 1995, 95(4):1846-53.

5. Albu JB, Murphy L, Frager DH, Johnson JA, Pi-Sunyer FX: Visceral fat and racedependent health risks in obese nondiabetic premenopausal women. Diabetes 1997, 46(3):456-62.

6. Bonora E: Relationship between regional fat distribution and insulin resistance. Int J Obes Relat Metab Disord 2000, 24(Suppl 2):S32-S35.

7. Ross R, Aru J, Freeman J, Hudson R, Janssen I: Abdominal adiposity and insulin resistance in obese men. Am J Physiol Endocrinol Metab 2002, 282(3):E657-E663.

8. Ross R, Fortier L, Hudson R: Separate associations between visceral and subcutaneous adipose tissue distribution, insulin and glucose levels in obese women. Diabetes Care 1996, 19(12):1404-11.

9. Despres JP, Nadeau A, Tremblay A, et al: Role of deep abdominal fat in the association between regional adipose tissue distribution and glucose tolerance in obese women. Diabetes 1989, 38(3):304-9.

10. Berg $\mathrm{AH}$, Scherer PE: Adipose tissue, inflammation, and cardiovascular disease. Circ Res 2005, 96(9):939-49.

11. Lara-Castro C, Weinsier RL, Hunter GR, Desmond R: Visceral adipose tissue in women: longitudinal study of the effects of fat gain, time, and race. Obes Res 2002, 10(9):868-74.

12. Bandura A: Self-efficacy: toward a unifying theory of behavioral change. Psychol Rev 1977, 84(2):191-215.

13. Thompson SC: Will it hurt less if i can control it? A complex answer to a simple question. Psychol Bull 1981, 90(1):89-101.

14. Seligman ME, Rosellini RA, Kozak MJ: Learned helplessness in the rat: time course, immunization, and reversibility. J Comp Physiol Psychol 1975, 88(2):542-7.

15. Mirowsky J, Ross CE: Eliminating defense and agreement bias from measures of the sense of control: A $2 \times 2$ index. Social Psychology Quarterly 1991, 54(2):127-45.

16. Thompson SC, Spacapan S: Perceptions of control in vulnerable populations. Journal of Social Issues 1991, 47:1-21.

17. Ajzen I, Fishbein M: Understanding attitudes and predicting social behaviour Englewood Cliffs, NJ: Prentice-Hall; 1980

18. Ajzen I: The theory of planned behaviour. Organizational Behaviour and Human Decision Processes 1991, 50:179-211.

19. Baban A, Craciun C: Changing health-risk behaviors: A review of theory and evidence-based intervetions in health psychology. Journal of Cognitive and Behavioral Psychotherapies 2007, 7(1):45-67.

20. Keys A, Fidanza F, Karvonen MJ, Kimura N, Taylor HL: Indices of relative weight and obesity. J Chronic Dis 1972, 25(6):329-43.

21. SPSS Statistics v17.0 [computer program]. Chicago, IL; 2007.

22. Carroll JF, Chiapa AL, Rodriquez M, et al: Visceral fat, waist circumference, and BMI: impact of race/ethnicity. Obesity (Silver Spring) 2008, 16(3):600-7.

23. Cardarelli KM, Vernon SW, Baumler ER, Tortolero S, Low MD: Sense of control and diabetes mellitus among U.S. adults: a cross-sectional analysis. Biopsychosoc Med 2007, 1:19.

24. Adolfsson B, Andersson I, Elofsson S, Rossner S, Unden AL: Locus of control and weight reduction. Patient Educ Couns 2005, 56(1):55-61.

25. Nir Z, Neumann L: Relationship among self-esteem, internal-external locus of control, and weight change after participation in a weight reduction program. J Clin Psychol 1995, 51(4):482-90.

26. Krause N, Stryker S: Stress and well-being: the buffering role of locus of control beliefs. Soc Sci Med 1984, 18(9):783-90. 
27. Surgenor LJ, Horn J, Hudson SM: Links between psychological sense of control and disturbed eating behavior in women with diabetes mellitus. Implications for predictors of metabolic control. J Psychosom Res 2002, 52(3):121-8.

28. Milaneschi Y, Bandinelli S, Corsi AM, et al: Personal mastery and lower body mobility in community-dwelling older persons: the Invecchiare in Chianti study. J Am Geriatr Soc 2010, 58(1):98-103.

29. Norman P: Health locus of control and health behaviour: An investigation into the role of health value and behaviour-specific efficacy beliefs. Personality and Individual Differences 1995, 18(2):213-8.

doi:10.1186/1751-0759-5-12

Cite this article as: Cardarelli et al:: The relationship between perceived sense of control and visceral adipose tissue - the North Texas Healthy Heart Study. BioPsychoSocial Medicine 2011 5:12.

\section{Submit your next manuscript to BioMed Central} and take full advantage of:

- Convenient online submission

- Thorough peer review

- No space constraints or color figure charges

- Immediate publication on acceptance

- Inclusion in PubMed, CAS, Scopus and Google Scholar

- Research which is freely available for redistribution

Submit your manuscript at www.biomedcentral.com/submit 